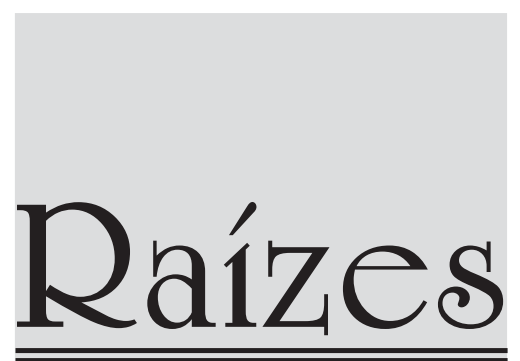

Vol. 27, $\mathrm{N}^{\mathrm{o}} 1$, jan. - jun./2008

Trabalho recebido em 05/01/2008

Aprovado para publicação em 22/05/2009

\title{
TRABALHADORES RURAIS: A NEGAÇÃO DOS DIREITOS
}

\author{
$\overline{\text { Maria Aparecida de Moraes Silva }}$
}

\section{RESUMO}

Este texto discute a situação dos trabalhadores rurais, especificamente, os cortadores de cana no estado de S. Paulo à luz dos direitos humanos como princípios universais. A negação dos direitos trabalhistas e o desrespeito à capacidade humana durante o trabalho tem ocasionado várias mortes, supostamente, por exaustão e também contribuído para a depredação da força de trabalho de milhares de trabalhadores nos últimos anos. Os métodos empregados para aumentar os níveis de produtividade exigidos pelas usinas reduzem os poros da jornada de trabalho e anulam as possibilidades dos espaços da micro-resistência. Contudo, outras formas de resistência tem sido produzidas, envolvendo outros atores sociais, alargando o campo da luta de classes e promovendo outras reivindicações, além daquelas circunscritas ao universo da relação capital e trabalho, quais sejam, aquela relacionadas aos direitos humanos.

Palavras-chave: direitos humanos, super exploração, cortadores de cana em São Paulo

\section{RURAL WORKERS: THE DENIAL OF HUMAN RIGHTS}

\section{ABSTRACT}

This text discusses rural workers' situation, particularly those who work in sugar cane extraction in São Paulo State, taking as reference the Human Rights as universal principles. The denial of workers rights and the disrespect to the human capacity along their work has caused many deaths, due to exaustion and has also contributed to the depredation of work force of million of workers in last years. Methods used to increase productivity levels which are demanded by sugar production stations decrease working day windows and weak eventual possibilities of micro-resistence. However, other forms of resistence have been produced, envolving other social actors, widening the field of classes struggles and eliciting other requests besides those related to the universe of the relationship between capital and work, it means those related to the Human Rights.

Key Words: Human Rights, super exploitation, sugar cane, workers from São Paulo

Maria Aparecida de Moraes Silva. Professora Livre-docente/UNESP. Colaboradora do PPG/Geografia/ UNESP/PP e do PPG/Sociologia/UFSCar. Pesquisadora do CNPq.E-mail: maria_moraes@terra.com.br 


\section{INTRODUÇÃO}

Costuma-se dizer que, atualmente, se vive uma nova ordem social, ou seja, um novo ordenamento da sociedade, tanto do ponto de vista interno como das relações inter-sociedades, que são estruturadoras da vida das pessoas. No final do século XX, debateu-se muito a chamada crise dos paradigmas, o fim das certezas e a necessidade de uma nova concepção de mundo, além dos efeitos do processo de mundialização do capital.

De início, os avanços tecnológicos, marcados pela internet, pelas comunicações digitais, foram interpretados como o novo modus vivendi e, mais precisamente, foram vistos como sinais de uma nova era redentora, capaz de levar o progresso aos mais distintos cantos do globo terrestre. Mundos isolados teriam, a partir de então, a oportunidade de inserção na nova ordem social. Aos poucos, no entanto, estas nuvens inebriantes foram sendo dissipadas. As diferentes realidades revelaram as conseqüências deste processo: desemprego, exclusão social, acirramento das imigrações internacionais com o aprofundamento das discriminações raciais e sociais internas e entre os países pobres e ricos, desagregação de muitas culturas, além da perda de muitos direitos conquistados ao longo de muitas décadas pelos movimentos sociais e pela falência do Estado em muitos setores. A realidade deste processo, conhecido como neoliberalismo, caracterizado pelo predomínio do capital financeiro, mostrou que os interesses privados de grandes empresas internacionais prevaleceram em detrimento das condições sociais da grande maioria da população, sobretudo os mais pobres, as mulheres, os negros, as crianças, os idosos, os indígenas e outras "minorias" sociais e étnicas. No que tange à cidadania, sabe-se que ela se acha articulada aos direitos e, portanto, foi igualmente atingida pelo retrocesso das conquistas ao longo de muitas décadas, em várias partes do mundo.

O Brasil, desde os finais da década de 1980, ao ingressar na era neoliberal do capitalismo financeiro internacional, vem sofrendo as conseqüências impostas por in- teresses alienígenas, relacionados aos fins lucrativos do mercado, ao desmonte do parque industrial (Biondi, 1999) e ao influxo dos direitos sociais dos cidadãos, na verdade, dos não cidadãos (Covre, 1986).

Diante desse quadro, o objetivo neste texto é tecer algumas considerações sobre a situação concreta dos trabalhadores rurais, particularmente, os cortadores de cana, no estado de S. Paulo, levando-se em conta não somente a não observância dos direitos trabalhistas como também a não efetividade dos direitos humanos do trabalho, no contexto da atual fase de desenvolvimento da produção canavieira, marcada pela presença de grandes grupos empresariais, nacionais e estrangeiros ${ }^{1}$.

As discussões serão articuladas em torno dos seguintes eixos: surgimento e evolução dos direitos humanos; medidas adotadas pelas empresas visando o aumento da produtividade do trabalho; a legislação trabalhista, especificamente a NR 31 e seu descumprimento; a ação do MP e MPT, novos sujeitos no processo de alargamento do campo das contradições entre capital e trabalho.

\section{SURGIMENTO E EVOLUÇÃO DOS DIREITOS HUMANOS}

A questão dos direitos humanos sempre esteve ligada a uma profunda contradição social entre homem e sociedade, e entre o indivíduo e seus demais congêneres. Durante muitos séculos, principalmente durante o período medieval, a Igreja Católica procurou resolver este conflito por meio da idéia da relação entre homem e eternidade, no intuito de diminuir o interesse do homem pela vida em sociedade, substituindo a sociedade pelo reino de Deus a ser alcançado depois da vida transitória na terra (Mbaya, 1997, p. 17).

$\mathrm{Na}$ Idade Média, a sociedade se achava dividida em senhores e servos e se caracterizava pela visibilidade das diferenças sociais entre estas duas camadas sociais. Portanto o artifício religioso era uma maneira pela qual os pobres - os excluídos do poder e dos direitos de que gozavam os dominantes -, encontrariam o refúgio para suas almas e também o consolo para suas desgraças terrenas.

\footnotetext{
1 Em 2006, 3,4\% dos capitais investidos em usinas eram estrangeiros. Em 2007, espera-se que estes valores subam para 5,0\%. Em 10 anos, seriam 50,0\%, segundo as palavras do usineiro Maurílio Biaggi Filho. Os maiores exportadores de álcool são: Coimex, Crystalsev, Copersucar, Cosan e Petrobrás. Em 4 anos, serão investidos US\$ 2,5 bilhões na produção de álcool e 77 usinas serão construídas até 2012. Suplemento Agrícola do Estado de São Paulo, 21 de fevereiro de 2007. No ano de 2006, houve a compra de 63\% da Usina Cevasa no município de Patrocínio Paulista pelo grupo norte-americano Cargil, e neste ano de 2007, a Louis Dreyfus Commodities Bionergia, subsidiária brasileira do grupo francês Louis Dreyfus comprou 4 usinas do Grupo pernambucano Tavares de Melo, em Mato Grosso do Sul, Paraíba e Rio Grande do Norte (folha de S. Paulo, 16 de fevereiro de 2007 , B 9).
}

Raízes, Campina Grande, vol. 27, nº 1, p. 29-42, jan./jun. 2008 
Esta situação perdura até a Revolução Francesa, quando a burguesia toma o poder, destituindo os nobres e a Igreja. Uma das primeiras medidas da revolução burguesa foi a Declaração dos Direitos do Homem, por meio da qual eram suprimidas todas as desigualdades sociais, sem discriminação de credo ou cor. "Os homens nascem livres e iguais em direitos, e as distinções sociais não podem fundar-se senão na utilidade comum. (Art. $\left.1^{\circ}\right)$. Toda sociedade política tem por fim conservar os direitos naturais e imprescritiveis do homem. Estes direitos são a liberdade, a propriedade, a segurança e a resistência contra a opressão (Art. $2^{\circ}$ ).

Um dos princípios básicos desta Declaração era o de que todos os cidadãos eram iguais perante a lei, e esta assertiva era fundamentada no jusnaturalismo, defendido por filósofos, como Rousseau e Locke, e que vão influenciar várias constituições de muitos países, inclusive a Declaração Universal dos Direitos do Homem, de 1948, formulada pela ONU (Organização das Nações Unidas). O jusnaturalismo, em síntese, preconizava que a igualdade dos seres humanos era natural e esta concepção está explicitada na Declaração Universal dos Direitos Humanos de 1948. "Todos os homens nascem livres e iguais em dignidades e direitos". Segundo Bobbio (1992, p. 29), esta é uma maneira diferente de dizer que todos os homens são livres e iguais por natureza. Vale a pena também lembrar a frase de Rousseau: "O homem nasceu livre e por toda parte encontra-se a ferros".

$\mathrm{Na}$ realidade, os homens não nascem livres nem iguais na sociedade burguesa. "São livres e iguais em relação a um nascimento ou natureza ideais, que era precisamente a que tinham em mente os jusnaturalistas quando falavam em estado de natureza. A liberdade e igualdade dos homens não são um dado de fato, mas um ideal a perseguir; não são uma existência, mas um valor; não são um ser, mas um dever ser" (Bobbio, 1992, p. 29). Desta sorte, fica evidente a grande contradição existente entre os ideais de liberdade proclamados pelos jusnaturalistas e a realidade das sociedades burguesas erigida sobre as bases da desigualdade social. A grande diferença em relação à sociedade medieval ou antiga é que, agora, as desigualdades são e devem ser mascaradas pela ideologia dominante, enquanto naquelas sociedades a condição de servo ou escravo se ancorava na visibilidade, isto é, as próprias leis e normas expli- citavam as diferenças e desigualdades sociais existentes.

Muitos autores já se debruçaram sobre a análise da cidadania e dos direitos (Vieira, 1998; Santos, 1992; Martinez, 1996; Covre, 1980; Chaú́, 1989). Portanto não cabe aqui repetir aquelas reflexões. O que é importante a ser enfatizado é a forma pela qual a sociedade burguesa é encoberta pela ideologia da liberdade e igualdade. Estes dois princípios, na verdade, foram sendo erigidos desde o século XVIII pelos iluministas, princípios estes que vislumbravam a construção de uma outra sociedade, diferente daquela existente. O primeiro passo era a garantia de homens livres para o trabalho, sem as marcas da escravidão e servidão; o segundo, a garantia de uma igualdade para mascarar as profundas desigualdades. A igualdade, como princípio, fundamentava-se na equalização das mercadorias enquanto valores de troca. Do mesmo modo, os homens deveriam ser equalizados, abstraindose as suas diferenças, a fim de se criar o intercâmbio entre eles, tal como havia no reino das mercadorias.

Assim foi sendo gestado, em nível de representações, um conjunto de abstrações, de idéias invertidas sobre a nova ordem social prestes a ser implantada. A Revolução Francesa foi o marco político e social por meio do qual estes princípios foram universalizados. Como foi dito acima, estes princípios instituíram direitos, que não foram dados de fato, mas seriam um ideal a perseguir. A nova sociedade, criada pelos princípios revolucionários, ao mesmo tempo em que instituía teoricamente estes princípios, na prática negava-os por meio do véu encobridor da ideologia ${ }^{2}$. Este processo de encobrimento das desigualdades sociais só pode ser revelado por meio de um contra-processo de conscientização social em torno de lutas e reivindicações. Esta tem sido uma das grandes empreitadas das sociedades modernas, que, por meio dos distintos grupos sociais, tais como, mulheres, pobres, negros, crianças, migrantes, estrangeiros, grupos religiosos e outros, lutam por direitos idealmente existentes, porém realmente negados.

"A cidadania pode começar por definições abstratas, cabíveis em qualquer tempo e lugar, mas para ser válida deve poder ser reclamada. A metamorfose desta liberdade teórica em direito positivo depende das condições concretas, como a natureza do Estado e do regime,

\footnotetext{
2 Adota-se aqui a pressuposição, segundo a qual, a ideologia é um conjunto de idéias que mascaram a realidade, dado que é somente por intermédio deste velamento que os interesses da classe dominante possam se tornar dominantes sobre o conjunto da sociedade. Portanto, há uma verdadeira inversão dos valores particulares da classe dominante, transformados em interesses universais.
}

Raízes, Campina Grande, vol. 27, nº 1, p. 29-42, jan./jun. 2008 
o tipo de sociedade civil em movimento. É por isso que desse ponto de vista a situação dos indivíduos não é imutável, mas está sujeita a retrocessos e avanços" (Santos, 1993, p. 8).

Tais reflexões conduzem ao fato de que a prática dos direitos e da cidadania só se efetivará no ato do fazer, do acontecer histórico, isto é, quando as ações dos diferentes grupos sociais e mesmo dos indivíduos forem dirigidas pela busca da desalienação. Neste ponto, também cabem alguns esclarecimentos. $\mathrm{O}$ que se entende pelo processo de alienação? Este conceito foi largamente estudado por vários pensadores, dentre eles K. Marx ${ }^{3}$. Sinteticamente, pode-se afirmar que a alienação é um processo ${ }^{4}$ que diz respeito à várias situações e momentos históricos. Inicialmente, considerando as origens da sociedade capitalista, houve um processo de expropriação do campesinato, principalmente inglês, por meio das mudanças das formas de propriedade, que, ao transformarem as terras dos camponeses em pastagens para as ovelhas, dado que a indústria de tecidos necessitava da matéria-prima (lã), provocaram a formação de um contingente de pessoas sem eira nem beira, cuja única saída foi a migração para as cidades em busca de trabalho nas indústrias. Num segundo momento, estes camponeses que perderam as terras, os instrumentos de trabalho, já transformados em operários, passaram a sofrer um outro processo de perda, identificado pela negação de seus saberes. A industrialização, iniciada com as manufaturas, exigia um conjunto de trabalhadores não correspondentes àquele dos camponeses-artesãos ${ }^{5}$. Foram obrigados a exercer um outro tipo de trabalho, além de obedecer às ordens de mestres e contra-mestres, portanto passaram a ser subordinados no ato do trabalho. Pouco a pouco foram se transformando em meros fornecedores de força de trabalho, sem terem o domínio do processo de produção e sem conhecerem as diferentes etapas deste processo, dado que foram inseridos numa divisão do trabalho controlada pelos donos das empresas, divisão que, cada vez mais, parcelizava-os e definia como partícipes de um mero ajuntamento de executores de um trabalho do qual conheciam apenas as partes. Desta sorte foi se completando o processo de alienação, que, ao fim e ao cabo, nada mais é do que indivíduos que mantêm entre si uma relação de estranhamento, de desconhecimento mútuo. Produz-se, assim, ainda segundo este autor, a sociedade do Ter e não a do Ser. Os indivíduos vão deixando de Ser para se preocupar com o Ter, isto é, vão se transformando em compradores, em consumidores de mercadorias e fornecedores de força de trabalho.

Deste conjunto de reflexões, pode-se estabelecer um nexo entre aquelas citadas anteriormente sobre a ideologia. Indivíduos alienados, envoltos por uma ideologia mascaradora da realidade, são os produtos desta sociedade. Porquanto os indivíduos não são meramente produtos sociais, eles são também produtores de script, estando neste contexto a luta pelos direitos e pela cidadania. O significado pleno de cidadania se alia aos direitos a serem conquistados e também aos deveres. A cidadania, portanto, tem um pé fincado nos direitos e o outro nos deveres. Quais seriam estes deveres? "Ser o (cidadão) o próprio fomentador da existência dos direitos a todos, ter responsabilidade em conjunto pela coletividade, cumprir as normas e propostas elaboradas e decididas coletivamente, fazer parte do governo, direta ou indiretamente, ao votar, ao pressionar através dos movimentos sociais, ao participar das assembléias - no bairro, sindicato, partido ou escola. E mais: pressionar os governos municipal, estadual, federal e mundial (em nível de grandes organismos internacionais como o Fundo Monetário Internacional- FMI (Covre, 1991, p. 9).

Vale a pena insistir que, no decorrer do tempo, há uma evolução tanto dos direitos como da cidadania e, conseqüentemente, há mudanças segundo os países e regiões. Tais mudanças ocorrem em razão das dinâmicas das diferentes sociedades e também das lutas e dos movimentos sociais. Por exemplo, no Brasil, atualmente, assistese às ações do Movimento dos Sem Terra, em razão das profundas desigualdades de nossa sociedade, produzidas pela concentração de renda e riqueza. A luta destes trabalhadores por terra insere-se num quadro maior de rei-

\footnotetext{
${ }^{3}$ K. Marx refere-se a este processo em várias passagens de sua obra, tais como, em Os Manuscritos econômico-filosóficos e no capítulo sobre a Mercadoria, em $O$ capital.

${ }^{4}$ A idéia de processo envolve as mudanças, as contradições, os conflitos durante um tempo determinado.

${ }^{5}$ Este momento de transição da sociedade rural para a urbana, da transformação do campesinato em operariado, no caso inglês, foi marcado por um intenso processo de disciplina e controle. Na França, tais transformações ocorreram mais tarde, no final do século XIX. Em ambas as realidades históricas, a educação foi proposta para propiciar a integração social, evitando os conflitos e o acirramento das contradições sociais.
}

Raízes, Campina Grande, vol. 27, nº 1, p. 29-42, jan./jun. 2008 
vindicações por direitos à saúde, à escola, ao emprego e ao trabalho, enfim, à inclusão social. Podemos aí inserir o exemplo dos trabalhadores rurais nos canaviais paulistas. As 17 mortes ocorridas por exaustão no período de 2004 a 2006, estão sendo interpretadas como desrespeito aos direitos humanos, aos princípios de dignidade, liberdade e segurança.

Os contratos legais das sociedades capitalistas estipulam regras para a exploração da força de trabalho dentro de limites que possam garantir a reprodução da força de trabalho e a continuidade da presença do trabalhador no mercado laboral, enquanto vendedor da mercadoria que lhe pertence, que é sua força de trabalho. No momento em que estes limites são desrespeitados, as regras do contrato, que pressupõe pessoas livres juridicamente, deixam de operar, e, conseqüentemente, a noção de liberdade é questionada. Portanto, os direitos humanos, definidos por sua universalidade, garantidores da condição da liberdade civil, são também colocados em xeque. Nesse momento caem as máscaras da liberdade civil, pondo à mostra uma situação não condizente com a ideologia da sociedade capitalista, pautada na liberdade e na igualdade, contrária à escravidão. Um escravo é diferente de outros trabalhadores porque é, legalmente, proprietário de um senhor. Um escravo não é uma pessoa, mas uma coisa, uma res, uma mercadoria que pode ser comprada ou vendida, como qualquer outro bem. O trabalhador assalariado, como vimos, é juridicamente livre e civilmente igual; ele participa voluntariamente de um contrato de trabalho e em troca recebe um salário.

"O contrato de trabalho exemplifica a liberdade individual de dispor de sua propriedade como ele, e somente se ele achar conveniente. O contrato é, portanto, essencial para o trabalho voluntário" ( $\mathrm{Pa}$ teman, 1993, p. 100, grifos da autora).

No entanto, o contrato institui o trabalhador como subordinado de seu patrão, dado que este o orienta em seu trabalho. Por outro lado, um patrão não é exatamente um senhor de escravo. O patrão possui direitos limitados e não direitos absolutos, como os senhores de escravos ( $\mathrm{Pa}$ teman, op, cit, , p, 102). A liberdade não é aqui entendi- da como fazer o que se quer, porém a liberdade de se submeter de maneira desejada, estipulada no contrato, no caso dos trabalhadores e, no caso dos patrões, isso pressupõe o respeito a estes limites, sendo um deles o uso da força de trabalho por um tempo determinado e não todo o tempo. Pateman (op. cit), cita a este respeito uma interessante passagem de Hegel:

"Posso delegar (a alguém) o uso de minhas habilidades por um período limitado, porque, baseado nesta limitação, minhas habilidades adquirem uma relação de exterioridade em relação à totalidade de meu ser. Ao alienar todo o meu tempo, tal como cristalizado em meu trabalho, e em tudo que produzo, estaria transformando em propriedade de outro a essência de meu ser... a minha personalidade" (Hegel, 1952, p. 67, apud Pateman, p. 217).

Quem, no entanto, possui poderes para fiscalizar estes limites do tempo estipulados nos contratos das sociedades modernas? Em princípio é o Estado, instância situada acima dos indivíduos. Os exemplos históricos revelam que a intervenção do Estado se faz no contexto das lutas sociais, das reivindicações das classes subalternas ${ }^{6}$.

Em nosso entender é deste contexto de reflexões que faz parte a situação dos trabalhadores rurais nos canaviais paulistas. Quando as notícias das mortes por exaustão vieram à tona, graças às denúncias da Pastoral do Migrante (Guariba), não somente representantes instituídos dos direitos humanos - Promotoria Pública - como também representantes da sociedade civil reivindicaram medidas contra as práticas atuais de exploração da força de trabalho, agora não mais traduzidas em termos de extensão da jornada de trabalho mais valia absoluta - mas da intensidade desta exploração - mais valia relativa -. O crescimento gigantesco dos níveis de produtividade pode ser visualizado por meio das seguintes cifras: em 1980, a média exigida no corte da cana girava em torno de 6 a 8 toneladas diárias; na década de 1990, estes números passam para 10 e a partir de 2000, para 12 a 15 toneladas! No que tange aos salários, cálculos do Sindicato de Trabalhadores Assalariados de Bebedouro mostram que antes de 1988, o piso salarial correspondia a 2,5 salários mínimos. Em

\footnotetext{
${ }^{6}$ Historicamente, este fato foi estudado por Marx, ao se referir à aprovação de leis que disciplinavam as relações de trabalho pelo Parlamento, baseado nos relatórios das fábricas inglesas, onde a jornada de trabalho, às vezes, ultrapassava 18 horas, levando à morte por exaustão, muitos operários, homens, mulheres e crianças. No Brasil, as primeiras lutas pela imposição dos limites da exploração da força de trabalho, ocorreram no início do século XX não somente nas cidades, sobretudo São Paulo, como também nas fazendas de café (Beiguelman, 1981).
}

Raízes, Campina Grande, vol. 27, n0 1, p. 29-42, jan./jun. 2008 
seguida, estes valores caíram para um pouco mais de 1

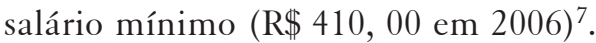

A fim de aprofundarmos a compreensão dos níveis desta exploração, faremos primeiramente uma exposição sobre os métodos empregados nos últimos anos pelas usinas para aumentar ainda mais os níveis de produtividade, sem promover alterações nos padrões tecnológicos, para, em seguida, analisarmos as regras instituídas pelo Ministério do Trabalho e Emprego (NR 31) para disciplinar o ambiente do trabalho, garantir a reprodução desta força de trabalho em condições minimamente compatíveis com as normas universalizantes dos direitos trabalhistas e humanos. Vale a pena acrescentar que o estado de S. Paulo é o maior produtor de cana do país e também aquele onde os níveis de produtividade são os maiores. Assim sendo, em 2003, do total da área de cana do país - 5.377.216 ha -, havia no estado de S. Paulo, 2.817.604 ha, portanto mais da metade da área plantada, enquanto a produtividade média do país era de $73.731 \mathrm{Kg} / \mathrm{ha}$, em S. Paulo, estes valores eram de 80.913, segundo dados do IBGE.

\section{COMO SE FORMA UM BOM CORTADOR DE CANA}

O aumento da exigência dos níveis de produtividade foi mais ainda incentivado pelo chamado Programa "Cana Limpa", que é um conjunto de normas que visam a melhoria do corte da cana por meio de novos métodos, sem alterações dos padrões tecnológicos, cujos efeitos são traduzidos em maior dispêndio de energia pelos trabalhadores. Tais normas foram elaboradas pelo SENAR (Serviço de Aprendizagem Rural), órgão ligado à entidade patronal FAESP (Federação da Agricultura do Estado de São Paulo), “(...) que tem como objetivo, organizar, administrar e executar em todo estado de São Paulo, o ensino da formação profissional e da Promoção Social Rurais dos trabalhadores e pequenos produtores rurais que atuam na produção primária de origem animal e vegetal, na agroindústria, no extrativismo, no apoio e na prestação de serviços rurais" (SENAR, 2004, p. 5).

A Formação profissional, segundo a cartilha produzida por este órgão, visa, sobretudo, o aumento da produtividade por meio da melhoria da qualidade do corte, da eliminação do chamado "mau cortador de cana", daquele que realiza pequenas resistências ao sistema de exploração imposto. A título de exemplo, citamos alguns pontos do conteúdo da Cartilha de Formação profissional:

- O profissional do corte da cana está relacionado a uma etapa da colheita que define padrão de qualidade da matéria-prima (p. 24);

- Corte bem feito significa preservação das soqueiras, pois a cana rebrota várias vezes, o que é essencial para elevar a produtividade e a produção (p. 25);

- Uso obrigatório dos EPIs (equipamentos de segurança individuais) (P. 27 e ss);

- Os EPIs relacionados são: boné com abas ou chapéus, toca árabe, óculos, luvas, mangotes, perneiras simples e com joelheiras, botinas com pontas ou biqueiras de aço e aventais ou saiotes. Em seguida, há as explicações das funções de cada um desses equipamentos (p. 28-33);

- Orientação sobre o uso das ferramentas de trabalho: podões, limas para amolar as lâminas (p. 34-41); Em relação a este item, há vários tipos de podões, tais como: de cabo curto, de cabo comprido, de cabo torto, com lâmina ou folha reta e com folha torta.

Em se tratando dos facões de cabo curto, segundo relatos dos trabalhadores, eles precisam aumentar a inclinação do corpo durante o corte, mais um agravante do sofrimento no trabalho. Para burlar esta imposição, há uma forma de resistência produzida no eito que é a troca de cabos do podão pelo próprio trabalhador. As usinas, na busca do aumento desenfreado de lucros, fornecem podões com cabos menores, a fim de diminuir os custos com os instrumentos de trabalho.

- A qualidade da matéria-prima, segundo as exigências do mercado, será conseguida basicamente nesta etapa do corte. Para isso é preciso:

- reduzir as impurezas minerais (terra) e vegetais: palha, folha e pontas de cana, evitando assim que sejam transportadas para a moagem, o que implicaria em elevação dos custos de transporte, maiores gastos com água e comprometimento do teor de sacarose, já que seus maiores índices estão concentrados na base da planta e não nos ponteiros;

- Realização de um corte perfeito, cuja execução deve

7 Em 2006, o SM era de $\mathrm{R} \$ 350,00$. 
seguir os seguintes preceitos (p. 47 e ss):

- Corte da cana em pé: o cortador deve trabalhar em sistemas de "braçadas" trazendo o feixe de cana para junto de seu corpo. Em seguida, inclina-se e realiza o corte rente ao solo, evitando assim o "toco alto";

- Corte da cana deitada ou caída ou cana de rolo: o cortador deve redobrar os cuidados, pois não é possível "abraçar a cana”, o que pode ocasionar toco alto, picação de cana ou desponte incorreto. No entanto, não há na cartilha informações sobre os procedimentos em caso de cana deitada. Como fazer para levantar a cana e abraçá-la? Aí reside mais uma fonte do dispêndio de energias. Assim sendo, o Sindicato de Cosmópolis desenvolveu um método capaz de diminuir um pouco este desgaste. O cortador leva consigo o gancho, um instrumento de madeira, preparado por ele mesmo, que substitui, na verdade, os movimentos com as pernas para alinhar a cana para o corte dos ponteiros, caso estes não sejam retirados antes de serem lançados nas leiras. A experiência adquirida durante o tempo de trabalho leva à criação de estratégias que visam a diminuição do sofrimento no trabalho. Assim sendo, o gancho, como invenção resultante da experiência laboral, acaba sendo um mecanismo de resistência do trabalhador. Este instrumento ameniza as dores nos braços e nas costas e evita o agravamento das dores nas pernas. O gancho não consta, portanto, das normas relativas aos equipamentos ou instrumentos que visam a capacitação dos trabalhadores.

Na cartilha, há uma ênfase no tocante ao corte rente ao solo, dado que em caso contrário as perdas seriam para a empresa e para os trabalhadores. As perdas para a empresa seriam: menor produção, riscos de ataques de pragas ou doenças e perda da sacarose. Para os cortadores, as perdas seriam: presença de toco seco, responsável pela diminuição da produtividade na próxima safra; necessidade de repasse da área mal cortada; maiores desgastes da lima e do podão; maior esforço físico; perda de tempo e risco de sofrer punições. Quanto ao corte dos ponteiros, as exigências são muitas, porque, ao contrário da base, é uma parte da cana com o mínimo teor de sacarose. Além do custo do transporte, caso não sejam descartados, há o aumento do teor de fibra e a diminuição do ATR (Açúcar total recuperável).

- A limpeza dos eitos. Além do corte perfeito, há a necessidade de deixar o eito limpo, para melhorar a qualidade da matéria-prima, diminuindo as impurezas materiais e vegetais. Assim sendo, os ponteiros devem ser afastados das bandeiras (montes) e das esteiras por, no mínimo $80 \mathrm{~cm}$. (p. 52);

- Modalidades do corte. Após o corte, como devem ser dispostas as canas para facilitar a ação dos guinchos? Há dois sistemas:

- Canas esteiradas: trata-se do sistema de dispor as canas tendo como referência a rua do meio do eito ( a metade da cana na $3^{\text {a }}$ rua para eitos de 5 ruas e na $4^{\text {a }}$ para eitos de 7 ruas). As canas devem ser alinhadas homogeneamente ao longo do eito. Caso contrário, elas escorregam durante o carregamento, aumentando desperdícios e bitucas (pedaços de cana caídos durante o carregamento). As pontas devem ser voltadas para o lado do cortador, a fim de diminuir seu esforço. A operação de carregamento exige muitos cuidados e seu sucesso depende da disposição das canas nas leiras.

- Canas amontoadas ou embandeiradas. Neste sistema, as canas são colocadas nos montes. As canas são cortadas e os ponteiros devem estar sempre voltados para o mesmo lado. A distância entre os montes varia de 1,5 a $3 \mathrm{~m}$. Além disso, devem ser limpas as laterais e os intervalos entre os montes impedindo que as impurezas sejam carregadas pelos guinchos.

\section{AÇÕES DOS MAUS CORTADORES: A RESISTÊNCIA MIÚDA ${ }^{8}$}

A intensidade do trabalho, aliada ao controle de fiscais e feitores, acabam por produzir o bom cortador de cana, cujo corpo disciplinado, domesticado, repete sucessivamente movimentos de inclinar-se, levantar-se, lançar a cana, alinhá-la, limpar as impurezas ao redor dos mon-

${ }^{8}$ Muitas dessas práticas de resistências foram relatadas por vários trabalhadores na década de 1990 durante minhas pesquisas. Ver a respeito, SILVA (1999).

Raízes, Campina Grande, vol. 27, nº 1, p. 29-42, jan./jun. 2008 
tes, logrando assim o corte perfeito, essencial para a qualidade da matéria-prima, da diminuição dos custos de produção e aumento dos lucros da empresa. O eito, portanto, é um espaço extremamente importante da cadeia produtiva do açúcar e álcool. Neste momento, valeria a pena observar que, apesar das exigências impostas, a resistência miúda ocorre nos poros do sistema de dominação e exploração, denominadas na cartilha, de ações não desejáveis no corte manual (p. 55).

- Picação de cana. Trata-se do corte dos ponteiros após serem lançados aos montes, ação que aumenta a produtividade do trabalho, mas implica em perdas para as empresas, já que muitos ponteiros acabam não sendo cortados e levados para a moagem, resultando em perdas, como já vimos em linhas atrás.

- Cama de gato ou cambalacho. São as canas não cortadas, escondidas em baixo dos montes ou esteira. Esta ação traz prejuízos, tais como: aumenta o desperdício de matéria-prima, prejudica a brotação, aumenta o serviço dos bituqueiros. Trata-se de uma ação passível de punições e advertências.

- Jacaré, teimosa, ou cana mamando. Trata-se da cana não cortada, somente tombada com a botina e escondida sob as canas amontoadas nas esteiras ou bandeiras. Os prejuízos são os mesmos, além do arranquio das soqueiras, impedindo a rebrotação.

- Telefone. Trata-se da ação de não cortar uma ou duas ruas de cana, voltando depois de mais ou menos $40 \mathrm{~m}$ para igualar o eito. Esta prática possibilita a repicagem de ponteiros ou pés na esteira ou nos montes, provocando perda de produção.

- Baião-de-dois ${ }^{9}$. Consiste no corte da cana por dois trabalhadores num mesmo eito. Esta prática proibida (porque desalinha a cana nos montes) pode ser, no entanto permitida, quando interessa à empresa: nos casos de necessidade de liberar a área, quando há falta de matéria-prima para a moagem, ou no final do horário de trabalho, para igualar os eitos ou terminar o corte de uma certa área.

Segundo as orientações contidas no manual de capacitação dos profissionais do corte da cana, o sucesso da fase seguinte ao corte, a do carregamento, depende do corte bem feito, a fim de se evitar os prejuízos referentes ao transporte de ponteiros, palhas e outras impurezas, detectados no momento da análise do Laboratório do $\mathrm{Pa}$ gamento de Cana.

Notícias recentes, veiculadas pelo JornalCana ${ }^{10}$, revelam que este curso de capacitação tem alcançado seus principais objetivos. Além da participação cada vez mais crescente das usinas interessadas por este programa, os resultados apontam para a redução em até $70 \%$ das impurezas da cana. Desde 2004, data de sua implantação, o programa já capacitou 110 mil cortadores e em 2007, a previsão é a incorporação de mais 50 mil. Vale a pena notar que na cartilha há menção à valorização do trabalhador, na medida em que fazendo um corte bem feito, ele se transforma num profissional, capaz de receber premiações como bicicleta e eletrodomésticos, caso siga as regras do curso de formação.

Os preceitos para a formação do bom cortador de cana fazem parte do contrato de trabalho, que, segundo as reflexões acima, é imposto aos trabalhadores. Estas normas instituem o trabalhador como subordinado da empresa, dado que esta o orienta em seu trabalho, definindo-lhe as regras precisas durante a execução das tarefas relativas ao ato de cortar e carregar a cana. Por outro lado, trata-se de um trabalho parcelado, alienado, pois o cortador não participa da organização e desconhece as demais fases do processo produtivo. Além do mais, os níveis de produtividade são conseguidos por meio de maior esforço despendido, sem, contudo haver aumento de salário, já que o preço é pago por tonelada cortada, segundo o método adotado do "campeão". Portanto, por detrás da ideologia da valorização do trabalhador, agora transformado em profissional do corte, esconde-se mais uma forma perversa de extração do sobretrabalho, sem custos para as empresas.

No entanto, em razão dos critérios impostos, vários depoimentos demonstram que este montante é muito maior, pois o cálculo da produtividade é feito a partir da transformação do metro em toneladas. Ou seja, a partir de cálculos aleatórios, a paridade é estabelecida em, por

\footnotetext{
9 Até o final da década de 1980, havia muitas mulheres empregadas no corte da cana, situação hoje praticamente inexistente. Muitas delas cortavam cana em conjunto, ou seja, por meio do baião-de-dois, a fim de aumentar a produtividade do trabalho e também como forma de amenizar as agruras do ambiente de trabalho, já que durante a jornada desenvolviam uma sociabilidade, capaz de diminuir as agruras do ambiente de trabalho. Ver a respeito, Silva (1999).

${ }^{10}$ Informações retiradas do site www.jornalcana.com
} 
exemplo, $\mathrm{X}$ metros $=\mathrm{X}$ toneladas. Este sistema é chamado "campeão", que consiste no seguinte: antes do corte, um técnico da usina recolhe três amostras de cana de cada talhão (área plantada). Estas canas são levadas para a usina e pesadas. A partir daí são fixados os valores correspondentes de metros e toneladas, segundo estimativas baseadas nas amostras colhidas. Entretanto, apesar dos critérios científicos e técnicos terem aperfeiçoado as variedades de cana - cada vez mais visando ao aumento do teor de sacarose -, as canas não possuem o mesmo peso, nem se encontram da mesma forma no momento do corte. Há canas deitadas, em pé, trançadas, as quais exigem diferentes esforços dos trabalhadores ${ }^{11}$.

Em suma, a imposição da média, aliada a estas estratégias adotadas pelas empresas no sentido de profissionalizar o cortador de cana, lograram o aumento da produtividade do trabalho, sem, contudo, aumentar o preço da força de trabalho. Este fato é um dos indicadores dos gigantescos lucros auferidos, que podem ser comprovados pelo Grupo Cosan, maior produtor de açúcar e álcool do país, segundo os dados abaixo:

COSAN em números (safra 05/06)

Faturamento líquido: $\mathrm{R} \$ 2,5$ bilhões

Empregos Diretos: 37 mil

Área Cultivada: 580 mil hectares
Moagem de Cana: 27,9 milhões t

Produção de Açúcar: 49 milhões de sacas

Produção de Etanol: $1.016 \mathrm{~m}^{3}$
Fonte: Cosan. Dados acessados a partir do site www.cosan.com.br

Gráfico 1. Vendas de Açúcar
Fonte: Cosan. Dados acessados a partir do site www.cosan.com.br

Gráfico 2. Vendas de Etanol
Fonte: Cosan. Dados acessados a partir do site www.cosan.com.br

Gráfico 3. Evolução da Receita Líquida

\footnotetext{
${ }^{11}$ Para evitar o roubo no momento da pesagem, o Sindicato de Trabalhadores rurais de Cosmópolis desenvolveu o método da quadra fechada,cuja descrição é a seguinte. De posse dos cadernos de metragem, obrigatoriamente oferecidos pela usina, tem-se o controle sobre o eito igualado, isto é, de todo o eito, e não apenas de algumas partes, segundo o processo de amostragem descrito anteriormente. Ademais, foi desenvolvido um software para computador - colocado na usina - capaz de controlar o peso da cana proveniente de todos as quadras (talhões), sob a fiscalização do sindicato. Segundo a sindicalista, os cálculos, advindos deste método, apontam para cifras muito superiores daquelas oferecidas pela usina. Em alguns casos, a partir de seus exemplos, 12 toneladas (segundo o campeão), na realidade, correspondem a 20, 25 ou até 30 toneladas (segundo a quadra fechada)! Em suma, além do sobre-valor captado pela relação de trabalho que fixa em R $\$ 2,20$ a tonelada cortada, há o roubo no momento da pesagem da cana na usina.
} 


\section{A NR 31 (Norma Regulamentadora de SEgU- RanÇa de SaÚde no TrabalHo na Agricultura, Pecuária, Silvicultura, ExploraÇão Flores- TAL E AQÜICULTURA) ${ }^{12}$}

Esta Norma Regulamentadora tem por objetivo estabelecer preceitos a serem observados na organização e ambiente do trabalho, de forma a tornar compatível o planejamento e o desenvolvimento das atividades da agricultura, pecuária, silvicultura, exploração florestal e aqüicultura com a segurança e saúde e meio ambiente do trabalho (NR 31, p. 1). Esta Norma estabelece como principal direito dos trabalhadores, ambientes de trabalho seguros e saudáveis. Disciplina os cuidados relativos ao uso de EPIs, transporte de trabalhadores, dos instrumentos de trabalho, dos agrotóxicos, das medidas relativas à alimentação nos locais de trabalho, das medidas em caso de acidentes de trabalho, do fornecimento de água, barracas sanitárias, das moradias, enfim dos direitos relacionados ao ambiente de trabalho.

No final do ano de 2005, em razão das denúncias das mortes ocorridas por exaustão, encaminhadas inicialmente ao Ministério Público, realizaram-se as duas primeiras Audiências Públicas na cidade de Ribeirão Preto/SP, chamadas pela Procuradoria Geral da República de São Paulo, Plataforma DHESC - Plataforma Brasileira de Direitos Humanos Econômicos, Sociais e Culturais - DHESC Brasil, com apoio institucional do Programa de Voluntários das Nações Unidas (UNV/PNUD) e da Procuradoria Federal dos Direitos do Cidadão - PGR/MPF.

Alguns excertos dos relatórios destas duas audiências atestam o não cumprimento das Regulamentações contidas na NR 31:

Durante a visita ao alojamento de trabalhadores migrantes, dentro da propriedade da Usina Bonfim, foram obtidas as seguintes informações e constatados os seguintes fatos:

Foram encontrados no alojamento os trabalhadores (cerca de 40) que se encontravam de folga no dia 04 , segundo o rodízio 5 por 1 .

As condições do alojamento se aproximam a de uma prisão. Em cada quarto existem 3 ou 4 camas. Os cômodos não têm janelas e as portas se abrem todas para um corredor interno. A área onde é feita a lavagem dos utensílios de trabalho é a mesma onde se lavam as marmitas e onde se obtém água para consumo individual. A presença de funcionários da empresa, durante todo o tempo em que estivemos no alojamento foi intensa, tentando impedir o acesso livre aos trabalhadores.

A maior parte dos trabalhadores no alojamento era de Minas Gerais. Foram recebidas denúncias de vários trabalhadores presentes no alojamento, que eles haviam sido aliciados por pessoas ligadas à empresa em suas cidades de origem ${ }^{13}$.

No Relatório da segunda Audiência Pública, presidida pela Dra. Cândida da Costa, a situação encontrada é assim descrita:

O turno de trabalho começa diariamente às $05 \mathrm{~h} 30 \mathrm{~min}$, sem hora prevista para terminar. Durante a jornada de trabalho, os trabalhadores são obrigados a cortar a cana o tempo inteiro, sem direito a pausa para descanso, parando para almoçar e sendo obrigados pelo chefe da turma a retomar o corte imediatamente, ação legalmente proibida, uma vez que a legislação trabalhista vigente determina como intervalo mínimo para almoço, o período de uma hora e máximo de duas, constituindo-se a obrigatoriedade de retomada do trabalho imediatamente pelo trabalhador numa violação do dispositivo legal em vigor. Chegam a cortar até 600 metros de cana por dia, o que seria equivalente a $\mathrm{R} \$ 30,00$ diários. A empresa fornece as ferramentas, botas e luvas. As roupas utilizadas no corte da cana são compradas por conta própria, não há o fornecimento de máscaras nem de óculos, o que obriga os trabalhadores a inalar a fuligem da cana queimada, e também a não proteger os olhos do contato com a fuligem e as partículas de cana.

Nas frentes de trabalho do Grupo Cosan não há ambulância nem trabalhador treinado e material de primeiros socorros para ser usado em caso de acidentes ou adoecimento de trabalhadores durante o turno de trabalho. Caso algum trabalhador seja acidentado ou adoeça no local de trabalho, tem de ser transportado pelo ônibus da Usina para a unidade de saúde mais próxima, entretanto, o município mais próximo do alojamento fica a duas horas de viagem. A inexistência de materiais médicos de primeiros socorros descumpre a determinação do artigo 168 , parágrafo $4^{\circ}$. e artigo 169 , ambos da Consolidação das Leis Trabalhistas.

a. No alojamento Jibóia, as condições de alojamento são precárias, em cada quarto existem quatro camas, e quatro armários de aço,

\footnotetext{
${ }^{12}$ NR 31 - Portaria do Ministério do Trabalho e Emprego, n. 86 de 03/03/2005.

${ }^{13}$ Relatoria Nacional para o Direito Humano à Alimentação Adequada, Água e Terra Rural. Relatório Preliminar, de visita para investigação das possíveis causas de morte de cortadores de cana de açúcar, no Estado de São Paulo, por possível sobrecarga de trabalho e alimentação insuficiente, segundo denúncia da Pastoral do Migrante de Guariba/SP, 4 de outubro de 2005, p. 5.
}

Raízes, Campina Grande, vol. 27, nº 1, p. 29-42, jan./jun. 2008 
nos quais os trabalhadores guardam seus pertences, e como o espaço é insuficiente, expõem-nos também no chão, sobre as camas, e suspendendo-os pelas paredes. Cada quarto conta apenas com uma janela pequena, as portas de todos os quartos apontam para uma mesma porta, estreita, que em caso de emergência (incêndio, por exemplo) impossibilitaria a fuga dos trabalhadores, colocando todos em risco. Os banheiros, localizados próximos ao quarto, não contam com chuveiro, contam apenas com uma pia pequena e um vaso sanitário com descarga os banhos são realizados em uma área coletiva com vários chuveiros.

b. As refeições são realizadas em um refeitório existente no local, próximo à cozinha, em horário fixo. Entretanto, os trabalhadores organizam-se para fazer as refeições sem interferência da administração local. Contam com uma nutricionista que freqüenta o local em dias alternados verificando se a dieta alimentar recomendada para os trabalhadores tem sido cumprida corretamente, embora alguns trabalhadores afirmem que a qualidade da comida não seja muito satisfatória. Há uma espécie de lavatório para os copos, onde eles retiram a água da torneira para beber, pois a usina não disponibiliza água filtrada para os trabalhadores;

c. O local onde lavam as roupas e utensílios usados no trabalho fica localizado na parte traseira de cada quarto, um pequeno lavatório composto por uma pia com torneira em precárias condições de higiene. Próximo a cada lavatório há uma fossa sanitária, algumas com a tampa danificada ou até cobertas com pedras, o que não proporciona o isolamento completo dos dejetos. É próximo a essas fossas sanitárias que se encontram os varais para colocação das roupas lavadas para secar ao sol $^{14}$.

No mês de novembro de 2006, 208 trabalhadores do Alojamento São Lourenço, da Usina Cosan Costa Pinto, em Charqueada, entraram em greve em razão das más condições de trabalho e de moradia. Segundo o relatório da Pastoral do Migrante/Guariba, havia trabalhadores acidentados, com cortes no joelho, sem receber atendimento, sem contar as reclamações acerca da alimentação, muitas vezes, já deteriorada, em função do calor. As condições de moradia eram bastante precárias, havendo fossas, exalando mau cheiro e banheiros localizados distantes do alojamento. As consultas médicas eram pagas ( $\mathrm{R} \$ 15,00)$, sem contar a existência de bar no alojamento, cujos preços das mercadorias eram superiores aos demais locais, o que confirma a velha prática do barra- cão. Ainda, segundo o relatório, os trabalhadores precisaram cortar cana de 7 ruas e são pagos por metro de cana cortada no valor de $\mathrm{R} \$ 0,06$, sendo que conseguem cortar em média, de 80 a 120 metros. Os que reclamam são ameaçados de sofrerem represálias, ficarem de gancho, isto é, impedidos de trabalhar por alguns dias. No dia 03/11/2006, fizeram uma caminhada até a sede da usina. No dia seguinte, no entanto, foram surpreendidos pela presença de policiais armados, que transferiram 40 trabalhadores para outro alojamento, cujo local não foi dito aos que ficaram. Ademais deste ato de violência praticado pelo poder policial, três deles receberam documentação com mandato de Interdito Proibitório, com prazo de 15 dias para recorrerem. Esta ação ainda se completava com a ameaça de pagamento de multa no valor de $\mathrm{R} \$ 3.000,00$ diários! $!^{15}$

No mês de fevereiro de 2007, portanto, antes do início da safra, novas fiscalizações nos canaviais durante a fase do plantio, realizadas pelos Ministério Público do Trabalho (MPT) e Ministério do Trabalho e Emprego (MTE) detectaram os seguintes fatos:

O Ministério Público do Trabalho (MPT), em conjunto com o Grupo Móvel de Fiscalização Rural do Ministério do Trabalho e Emprego (MTE) em São Paulo, iniciou no dia 12 de fevereiro uma nova série de ações de fiscalização para combater irregularidades trabalhistas nas lavouras de cana-de-açúcar no interior paulista. Os Procuradores José Fernando Ruiz Maturana e Luis Henrique Rafael ,do Ofício de Bauru da Procuradoria Regional do Trabalho da $15^{\text {a }}$ Região, acompanharam os auditores fiscais do MTE e constataram irregularidades no plantio de cana em várias lavouras da região. O principal problema encontrado foi a terceirização (e quarteirização) fraudulenta de mão-de-obra, considerada pelo MPT a maior causa da precarização nas relações do trabalho, além de irregularidades no meio ambiente de trabalho (falta de reposição de Equipamentos de Proteção individual - EPIs - excesso de jornada, não cumprimento de pausas para descanso, sanitários inadequados, falta de abrigos para as refeições, falta de exame médico admissional, transporte irregular e alojamentos precários), e nos contratos de trabalho e forma de pagamento. Existem aproximadamente 148 procedimentos ativos na PRT $15^{\mathrm{a}}$

\footnotetext{
${ }^{14}$ Relatoria Nacional para o Direito Humano ao Trabalho. Relatório da Missão realizada no período de 24 a 27 de outubro de 2005 na região de Ribeirão Preto/SP para a apuração de violações de Direitos Humanos de trabalhadores (as) canavieiros (as), 2005, p. 6-22.

${ }^{15}$ Relatório da Pastoral do Migrante ao Alojamento de São Lourenço, no dia 5/11/06. Notícia divulgada pelo ) O Imparcial, 10/11/06, p. 7.
} 
envolvendo usinas de cana-de-açúcar. As diligências em 2006, realizadas de maio a dezembro, percorreram lavouras de todo o Interior de São Paulo. Mais de 140 empresas foram fiscalizadas e autuadas, entre elas, 71 usinas de cana localizadas em 11 regiões - Piracicaba, Ribeirão Preto, Franca, São José do Rio Preto, Araçatuba, Araraquara, Bauru, Presidente Prudente, São Carlos, Campinas e Barretos. Todas as empresas fiscalizadas apresentaram irregularidades. Foram firmados 36 Termos de Compromisso de Ajustamento de Conduta (TAC), entre meio ambiente de trabalho, aliciamento, terceirização, contrato de trabalho e norma coletiva. Dezenas de ações civis públicas foram ajuizadas, e quatro conseguiram liminares. A fiscalização nos canaviais totalizou mais de 600 autos de infração lavrados pelos auditores fiscais do MTE. Este ano as fiscalizações foram antecipadas para permitir uma melhor cobertura de todas as atividades do setor canavieiro, desde o plantio, transporte e alojamento de migrantes que estão chegando para a safra de 2007, até o final da safra, no final do ano ${ }^{16}$.

Estes fatos demonstram dois aspectos importantes para nossas reflexões: o descumprimento da NR 31 e a não efetividade dos preceitos de valorização do trabalhador contidos no Programa Cana Limpa, que prevê várias recomendações de saúde, educação e meio ambiente, tais como água potável, transportada em galões térmicos, marmitas térmicas para evitar que a alimentação se deteriore em razão do calor, cuidados com os primeiros socorros, em caso de acidentes de trabalho, além de orientações sobre o uso de barracas sanitárias e ainda a preservação do meio ambiente, por meio do respeito às áreas de preservação permanente (APPs). Outro dado importante a reter é que qualquer manifestação coletiva não é interpretada como direito dos trabalhadores, mas, ao contrário, é passível de violência policial e ameaças judiciais, o que configura o caráter despótico da empresa, considerada a maior do setor sucroalcooleiro do país.

Durante todo o ano de 2006, foram veiculadas pela imprensa, e também pela mídia televisiva, inúmeras notícias referentes às condições precárias dos alojamentos de trabalhadores migrantes nas cidades e nas áreas de cana, ao desrespeito à NR 31, às queimadas de cana e seus efeitos nocivos às populações urbanas e rurais e também às fiscalizações desempenhadas pelo MPT e $\mathrm{MP}^{17}$.

\section{CONCLUSÕES}

O Estado de São Paulo é o principal produtor de açúcar e álcool do país, concentrando as maiores empresas

\footnotetext{
${ }^{16}$ Primeira Página, São Carlos, 18 de fevereiro de 2007, p. A 6.

${ }^{17}$ Eis alguns títulos de reportagens que apontavam irregularidades resultantes da produção canavieira. Força-tarefa autua usina na região. Folha de S. Paulo, Ribeirão, 26/10/05 C3. Queimadas crescem pelo $4^{\circ}$.ano consecutivo. Folha de S. Paulo, Ribeirão, 11/04/06, C 3. Força-tarefa desmonta alojamento de trabalhadores rurais. Jornal Primeira Página, São Carlos, 08/04/06, B3. Subdelegacia vai montar cerco às usinas e fazendas. Jornal Primeira Página, São Carlos, 15/03/06, B 1. Morro Agudo interdita 38 casas por falta de estrutura. Folha de S. Paulo, Ribeirão, 04/04, 2006, C 6. Usinas buscam responsabilidade social. Folha de S. Paulo, Ribeirão, 04/04/2006, C 7. Blitz multa moradias de migrantes em Pontal. Folha de S. Paulo, 16/03, 2006, C 1. Quatro usinas da região são processadas. Folha de S. Paulo, Ribeirão, 24/05/2006, C 5. Polícia investiga 11a. Morte de bóia-fria. Folha de S. Paulo, Ribeirão, 19/10/05, C 1 . Fiscalização em usinas aponta irregularidades. Folha de S. Paulo, Ribeirão, 26/10/2006, C4. Usina afirma que morte de bóiafria não se deve a condições de trabalho. Folha de S. Paulo, Ribeirão, 20/10/05, C 3. Ministério do Trabalho pára corte decana por falta de proteção. Folha de S. Paulo, Ribeirão, 07/06/2006, C4. 4 Blitze vê bóias-fria dormindo no chão, em bar e com fome. Folha de S. Paulo, Ribeirão, 30/05/2006, C 3. Usinas terão que dar casas para trabalhadores. Jornal 1ª . Página, São Carlos, 20/06/2006, B 3. Morre jovem que teve corpo queimado em usina (controle do fogo em canavial). Folha de S. Paulo, Ribeirão, 05/06/2006, c 1. Laudo vê "causa desconhecida" em morte de trabalhador. Folha de S. Paulo, Ribeirão, 07/07/2006, C 3. Pastoral divulga relatório sobre situação de cortadores de cana da usina Costa Pinto. O Imparcial, Araraquara, 10/ 11/2006, p.7. Bóias-frias são encontrados em condições sub-humanas na região de Bauru. O Imparcial, Araraquara, 14/09/2006, p. 6. Pardo vira "rio fantasma" após o desastre (atingido por vazamento de melaço de cana). Folha de S. Paulo, Ribeirão, 19/10/2003, C 1. Bóia-fria morreu após cortar 25 toneladas de cana. Folha de S. Paulo, Ribeirão, 27/10/2005, C 4. Força-tarefa vê possível intoxicação de trabalhador. Folha de S. Paulo, Ribeirão, 23/ 10/2005, C 14. Força-tarefa apura terceirização em usina. Folha de S. Paulo, Ribeirão, 6/10/2005, C 7. Blitz em Ribeirão vê aliciamento de bóia-fria. Folha de S. Paulo, Ribeirão, 05/10/2005, B10. Tecnologia faz trabalhador trabalhar mais. Folha de S. Paulo, Ribeirão, 18/09/2005, B 6. Mortes de bóias-frias serão investigadas. Folha de S. Paulo, Dinheiro, 28/09/2005, B 9. ONU apura mortes de trabalhadores na região. Folha de S. Paulo, Ribeirão, 13/09/2005, C 1. CETESB vê excesso de poluente na região. Média de registro de ozônio acima da superfície nos últimos 3 anos em 18 cidades está acima do tolerado. Folha de S. Paulo, Ribeirão, 8/11/2006, C 1. Usina Cosan nega a pagar piso salarial e greve continua (região de Andradina). O Imparcial, Araraquara, 16/09/2006, p. 6. Estado vê caos em moradia de bóias-frias. Balanço da Vigilância Sanitária aponta que, dos 229 locais vistoriados, 100\% deles estavam irregulares. Folha de S. Paulo, Ribeirão, 14/04/2006, C 1. Lavouras têm fiscalização antecipada em 2007 (fase do plantio). Primeira Página, São Carlos, 18/02/2007, A 1 e A 6. Usina veta cesta básica a cortador "fraco”. Folha de S. Paulo, Ribeirão, 05/10/2005, C 1. Usinas paulistas são processadas por irregularidade no trato de bóias-frias. Folha de S. Paulo Ribeirão, 28/05/2006, B 12. MPT formaliza 36 TACs com usinas na região em 2006. Primeira Página, São Carlos, 17/12/2006, A 7.
}

Raízes, Campina Grande, vol. 27, nº 1, p. 29-42, jan./jun. 2008 
que empregam tecnologias avançadas, graças ao desenvolvimento científico (biotecnologia e bioquímica) relacionado à descoberta de novas variedades de cana, ao aproveitamento do bagaço de cana para a produção de etanol ${ }^{18}$ e avanços na produção de máquinas utilizadas em diversas fases da colheita. Graças a isso, o país tem chamado a atenção de grandes empresas nacionais e internacionais que investem somas gigantescas na compra ou na instalação de novas usinas em várias regiões do país, além de muitos governantes estrangeiros interessados em parcerias para ampliação da produção do etanol, visto neste momento como uma das alternativas para a solução energética mundial ${ }^{19}$.

No entanto, estes avanços não são acompanhados de melhoria das condições dos trabalhadores. Muito ao contrário. Podemos estabelecer uma relação entre, de um lado, o avanço científico, tecnológico, lucros exponenciais e, de outro, o rebaixamento do preço da força de trabalho, o aumento da precariedade das condições de trabalho e de moradia, dos níveis de intensificação da exploração e do aviltamento dos direitos trabalhistas e humanos.

Nossa análise não interpreta esta realidade como paradoxo, mas como necessária aos níveis de acumulação mundializada. Cada vez mais, assistimos ao desmonte do poder de resistência dos trabalhadores em várias partes do mundo, sem contar o retrocesso dos direitos sociais, trabalhistas e humanos. O etanol produzido no Brasil possui os menores custos e, portanto, é um produto que possui um grande poder de concorrência nos mercados mundiais (U\$ 0,33 o litro de álcool, enquanto nos EUA, o litro de etanol, advindo do milho, custa $\mathrm{U} \$ 0,43$ ).

No entanto, este processo não é linear. As contradições cada vez mais se acirram não somente em razão da situação dos trabalhadores como também em razão de outras questões universais que englobam vários se- tores da sociedade, além da classe dos trabalhadores. $\mathrm{Na}$ realidade, hoje assistimos ao alargamento do campo das contradições, do qual participam os defensores dos direitos humanos (sociedade civil e MP) e do meio ambiente. Portanto, acreditamos que a universalização da produção capitalista e dos métodos de exploração e exclusão corresponde à emergência da participação de outros sujeitos sociais em lutas que, até então, eram circunscritas a determinadas particularidades históricas. Desta sorte, as ações do MP, do MPT, alguns Jornais e TVs, pesquisadores, estudantes de universidades e ONGs (algumas delas com vinculação internacional) nas lutas envolvendo a exploração dos trabalhadores rurais se constituem como um fato novo deste processo, pondo em relevo não somente o descumprimento da legislação trabalhista como também a negação dos direitos humanos universais ${ }^{20}$.

Neste embate, estes sujeitos não só se fazem presentes, como também possuem poderes, embora diferenciados, capazes de redirecionar os antagonismos, por meio de pressões em torno da obediência às normas legais, impondo, portanto, limites à voracidade destes capitais e exigindo do Estado a regulação das relações de trabalho, indo de encontro à desregulação e flexibilização impostas pelo capitalismo mundializado. No entanto, as ações de outros órgãos do estado, tais como os Ministérios de Minas e Energia, da Agricultura, além de bancos estatais, do poder executivo e dos lobbies de inúmeros parlamentares correspondem cada vez mais aos interesses das grandes empresas nacionais e estrangeiras.

Diante deste cenário, nos resta acreditar na utopia redentora de W. Benjamin, que consiste em desmistificar a história vista como progresso, representada como uma tempestade, por meio de um olhar marcado por uma dor profunda e inconsolável, mas também por uma profunda revolta moral (Löwy, 2005, p. 90 e ss).

\footnotetext{
${ }^{18}$ Este avanço científico deve-se À cooperação entre estado e empresas, tais como, Embrapa, IEA (Instituto Agronômico de Campinas), CTC (Centro Tecnológico Canavieiro), Fapesp e Copersucar. Sobre o aproveitamento do bagaço da cana para a produção do etanol, confira reportagem publicada na Folha de S. Paulo, Ciência, 12/02/2007, p. A10.

${ }^{19}$ Está programada para o dia 9/03/07, a vinda do presidente dos EUA ao Brasil, com o intuito de discutir as parcerias de produção do etanol entre os dois países. O objetivo é a instalação de usinas pertencentes à empresas norte-americanas, a fim de garantir o fornecimento necessário de etanol á demanda daquele país.

${ }^{20}$ Durante os últimos anos, dezenas de processos trabalhistas foram movidos por trabalhadores rurais, individual e coletivamente, visando o cumprimento da legislação. No município de Capivari, 50 trabalhadores migrantes entraram com uma ação contra o Grupo Cosan, tendo em vista a ameaça sofrida no ambiente de trabalho por feitor que impunham a média de 12 toneladas diárias. Segundo os autos do processo, os trabalhadores foram ameaçados de morte pelo feitor, fato interpretado pelo juiz como situação de trabalho escravo. Este processo acha-se ainda em fase de tramitação no Fórum daquela cidade.
} 


\section{REFERÊNCIAS BIBLIOGRÁFICAS}

BEIGUELMAN, P. Os companheiros de São Paulo. São Paulo: Gobal, 1981.

BIONDI, A. O Brasil privatizado. São Paulo: Fundação Perseu Abramo, 1999.

BOBBIO, N. A era dos direitos. 12.tiragem, Rio de Janeiro: Campus, 1992.

CHAUÍ, M. Cultura e democracia. 4.ed., São Paulo: Cortez, 1989.

COVRE, M. L. M. (Org.). A cidadania que não temos. São Paulo: Brasiliense, 1986.

COVRE, M. L. M. O que é cidadania. Coleção Primeiros passos, 8 a reimpressão, São Paulo: Brasiliense, 1999.

LÖWY, M. Walter Benjamin: aviso de incêndio: uma leitura das teses “Sobre o conceito de história”. São Paulo: Boitempo, 2005.
MARTINEZ, P. Direitos de cidadania. Um lugar ao sol. São Paulo: Scipione, 1996.

MBYATA, E-R. Gênese, evolução e universalidade dos direitos humanos frente à diversidade de culturas. Estudos Avançados, USP, n. 30, p. 17-41, 1997.

PATENAM, C. O Contrato sexual.Rio de Janeiro: Paz e terra, 1993.

SANTOS, M. O espaço do cidadão. 2.ed., São Paulo: Nobel,1993.

SENAR. Programa "Cana Limpa”. (Versão preliminar). São Paulo, 2004.

SILVA, M. A . M. Os errantes do fim do século. São Paulo: EDUNESP, 1999 